\title{
PENGARUH KUALITAS PELAYANAN PERIZINAN TERHADAP KEPUASAN MASYARAKAT PADA DINAS PENANAMAN MODAL DAN PELAYANAN TERPADU SATU PINTU (DPMPTSP)
}

\author{
Ratna Yulianingsih ${ }^{1}$, Tuti Hartati ${ }^{2}$ dan Mawarta Onida Sinaga ${ }^{3}$ \\ 1,2,3Administrasi Bisnis Terapan, Politeknik Negeri Jakarta \\ Email : 1 ratnayulianingsih97@gmail.com, ${ }^{3}$ mawarta.onida@bisnis.pnj.ac.id
}

\begin{abstract}
This study aims to determine the effect of licensing service quality on community satisfaction in the Bogor Regency DPMPTSP. This research uses quantitative research method. Data collection in Bogor Regency uses observation and questionnaire. Data processing technique using Likert scale, while the technique of data analysis using test Validity, Reliability, Normality, Linearity, simple linear regression analysis, simple correlation analysis, coefficient of determination and test of correlation coefficient significance or $T$ test. The results are: (a) The results of simple correlation coefficient test between the quality of service quality $(X)$ and the satisfaction of society $(Y)$ is 0.756 is strong, if it is concluded that there is strong correlation between variable $(X)$ and variable $(Y)$. (b) variable of service quality $(X)$ give influence to variable satisfaction $(Y)$ equal to $57,1 \%$ while the rest that is equal to $42,9 \%$ influenced by other factor not examined. (c) the result of t arithmetic is 10,633, while $t$ table is 1,663 so that 10,633 > 1,663 so that service quality of permit in DPMPTSP Bogor Regency has significant influence to the satisfaction of society.
\end{abstract}

Keyword: Service Quality, Public Service, Investment Service and One Stop Service.

\section{Abstrak}

Penelitian ini bertujuan untuk mengetahui pengaruh kualitas pelayanan perizinan terhadap kepuasan masyarakat pada DPMPTSP Kabupaten Bogor. Penelitian ini menggunakan metode penelitian kuantitatif. Pengumpulan data pada DPMPTSP Kabupaten Bogor menggunakan teknik observasi, dan kuesioner. Teknik pengolahan data menggunakan skala likert, sedangkan teknik analisis data menggunakan uji validitas, reliabilitas, normalitas, liniearitas, analisis regresi liniear sederhana, analisis korelasi sederhana, koefisien determinasi dan uji signifikansi koefisien korelasi atau uji T. Hasil penelitian menunjukkan bahwa : (a) Berdasarkan hasil uji koefisien korelasi sederhana antara variabel kualiatas pelayanan (X) dan kepuasan masyarakt (Y) bernilai 0,756 artinya kuat, jika disimpulkan bahwa terjadi hubungan yang kuat antara variabel $(\mathrm{X})$ dengan variabel (Y). (b) variabel kualitas pelayanan (X) memberikan pengaruh terhadap variabel kepuasan (Y) sebesar 57,1\% sedangakan sisanya yaitu sebesar 42,9\% dipengaruhi oleh faktor lain yang tidak diteliti. (c) hasil t hitung yang didapatkan adalah 10,633, sedangkan t tabel adalah 1,663 sehingga 10,633>1,663 sehingga kualitas pelayanan perizinan di DPMPTSP Kabupaten Bogor mempunyai pengaruh yang signifikan terhadap kepuasan masyarakat.

Kata Kunci: Kualitas Pelayanan, Pelayanan Publik, Dinas Penanaman Modal dan Pelayanan Terpadu Satu Pintu (DPMPTSP)

\section{PENDAHULUAN}

Manusia secara umum membutuhkan pelayanan dalam kehidupan sehari-hari. Pelayanan tidak bisa terlepas dari kegiatan yang dilakukan oleh manusia, banyak pelayanan yang ada di sekitar kehidupan manusia. Pada saat ini banyak aspek pelayanan yang ditawarkan untuk memudahkan kegiatan dan segala urusan, oleh karena itu manusia akan sangat terbantu dengan adanya pelayanan. 


\section{LATAR BELAKANG}

Pelayanan dalam bidang pemerintahan sangat penting perannya karena menyangkut kepentingan umum dan masyarakat. Terutama pada era presiden Jokowi ini, presiden Jokowi selalu menekankan kepada kepala daerah untuk mempermudah perizinan investasi atau penanaman modal dan memberikan pelayanan yang cepat, tepat dan akurat kepada masyarakat. Dasar pelayanan telah diatur sesuai dengan amanat UU No 22 Tahun 1999 yang kemudian diubah dengan UU No 32 Tahun 2004, pemerintah daerah berwenang untuk mengatur dan mengurus sendiri urusan pemerintahan menurut asas otonomi dan tugas pembantuan.

Pemberian otonomi luas kepada daerah diarahkan untuk mempercepat terwujudnya kesejahteraan masyarakat melalui peningkatan pelayanan, pemberdayaan, dan peran terhadap masyarakat. Dinas Penanaman Modal dan Pelayanan Terpadu Satu Pintu (DPMPTSP) Kabupaten Bogor adalah dinas yang mempunyai tugas dan fungsi memberikan berbagai macam perizinan untuk daerah dan masyarakat Kabupaten Bogor. Melalui Dinas ini diharapkan pelayanan perizinan dilaksanakan sesuai dengan asas. Kepastian hukum, tertib penyelenggaraan negara, kepentingan umum, keterbukaan, proporsionalitas, akuntabilitas, efesiensi dan efektivitas.

\section{Tujuan}

Berdasarkan perumusan masalah diatas, maka tujuan penelitian ini adalah mengetahui pengaruh kualitas pelayanan perizinan terhadap kepuasan masyarakat pada DPMPTSP Kabupaten Bogor.

\section{Rumusan Masalah}

Berdasarkan latar belakang yang sudah diuraikan diatas, maka dapat dirumuskan masalah perumusan pada penelitian ini adalah "apakah kualitas pelayanan perizinan berpengaruh terhadap kepuasan masyarakat pada DPMPTSP Kabupaten Bogor ?”.

\section{Tinjauan Pustaka \\ Pelayanan}

Kasmir (2008:15) menyatakan bahwa "pelayanan adalah tindakan atau perbuatan seseorang atau organisasi untuk memeberikan kepuasan kepada pelanggan atau nasabah”. Menurut Kotler dalam Wijaya (2011:150) jasa atau pelayanan adalah setiap tindakan atau perbuatan yang dapat ditawarkan oleh satu pihak kepada pihak lain, yang pada dasarnya bersifat intangible (tidak berwujud fisik) dan tidak menghasilkan kepemilikan sesuatu. Produksi jasa bisa berhubungan degan produk fisik maupun tidak.

Berdasarkan Undang-Undang Dasar Nomor 25 tahun 2009 tentang pelayanan publilk pasal 1 ayat 1menyataka pelayanan publik adalah kegiatan atau rangkaian kegiatan dalam rangka pemenuhan kebutuhan pelayanan sesuai dengan peraturan perundang-undangan bagi setiap warga Negara dan penduduk atas barang, jasa dan atau pelayanan administratif yang disediakan oleh penyelenggara pelayanan publik.

\section{Kualitas Pelayanan}

Menurut Goetsch dan Davi (1994) dalam Tony Wijaya (2011:152) "kualitas adalah kondisi dinamis yang berhubungan dengan produk, jasa, manusia, proses dan lingkungan yang memenuhi atau melebihi harapan”. Lewis Boom (1983) dalam Tony Wijaya (2011:152) "kualitas jasa adalah ukuran seberapa bagus tingkat layanan yang diberikan mampu sesuai dengan ekspektasi pelanggan”.

\section{Kepuasan Masyarakat}

Pengertian Kepuasan Menurut Richard Oliver (1997) dalam Tony Wijaya (2011:153) "kepuasan adalah tanggapan pelanggan atas terpenuhinya kebutuhannya”. Hal itu berarti penilaian bahwa keistimewaan tertentu barang atau jasa ataupung barang atau jasa itu sendiri 
memberikan tingkat kenyamanan yang terkait dengan pemenuhan kebutuhan tertentu. Tingakat kenyamanan juga mencakup pemenuhan kebutuhan yang di bawah harapan atau pemenuhan kebutuhan yang melebihi harapan pelanggan. Pengertian Kepuasan masyarakat menurut KEPMENPAN dapat dilihat pada NO KEP/25/MPAN/2/M.2004 dalam Rahmayanty (2012:96) adalah "hasil pendapat dan penilaian masyarakat terhadap kinerja pelayanan yang diberikan aparatur penyelenggara pelayanan publik".

\section{Dimensi Servqual}

Dimensi servqual yang dikemukakan oleh Parasuraman dalam Tony Wijaya (2011:155-166) adalah bukti langsung (tangible), yang meliputi fasilitas fisik, perlengkapan pegawai, dan sarana komunikasi. keandalan (reliability), yakni kemampuan memberikan pelayanan yang dijanjikan dengan segera, akurat dan memuaskan. daya tanggap (responsiveness), yaitu keinginan para staf dan karyawan untuk membantu para pelanggan dan memberikan pelayanan dengan tanggap. jaminan (assurance), yang mencakup pengetahuan, kemampuan, kesopanan dan sifat yang dapat dipercaya yang dimiliki para staf, bebas dari bahaya, resiko, atau keraguraguan. Empati (Emphaty), yang meliputi kemudahan dalam melakukan hubungan, komunikasi yang baik, perhatian pribadi dan memahami kebutuhan para pelanggan.

\section{METODE PENELITIAN}

Penelitian ini merupakan kategori penelitian kuantitatif dengan melakukan perhitungan terhadap uji yang dilakukan dalam menganalisis data. Penelitian ini mengetahui hubungan antar variabel kualitas pelayanan (X) dengan kepuasan masyarakat (Y).

\section{Populasi dan Sampling}

Populasi dalam penelitian ini adalah masyarakat yang membuat perizinan di
DPMPTSP. Hasil survey awal menunjukkan jumlah populasi penelitian ini sebanyak 600 orang. Penentuan sampel dihitung dengan menggunakan rumus Slovin dengan standard error $10 \%(0,1)$. Pengambilan sampel menggunakan teknik accidental sampling kepada 87 orang yang menjadi sample penelitian.

\section{Teknik Pengumpulan Data}

Data yang diperoleh dalam penelitian ini terdiri dari dua jenis, yaitu data primer dan data sekunder. Data primer yang didapat melalui menyebarkan kuesioner kepada masyarakat sebanyak 87 orang, dengan menggunakan skala likert serta data sekunder didapat dari referensi dan literatur.

\section{Teknik Pengolahan Data}

Pengolahan data pada penelitian ini menggunakan software SPSS versi 21. Proses pengolahan data dengan tahap editing, coding, tabulasi dan scoring.

\section{Teknik Analisis Data}

Analisis data dilakukan untuk menjawab permasalahan penelitian melalui tahap pengujian sebagai berikut:

a. Uji insturmen, terdiri dari uji validitas menggunakan korelasi product moment dengan kriteria $\mathrm{r}_{\text {hitung }}>\mathrm{r}_{\text {tabel, }}$ serta uji reliabilitas dengan nilai cronbarch alpha $>0,70$.

b. Uji analisis data, terdiri dari uji normalitas dengan kriteria nilai sig $>$ taraf signifikansi $\alpha$, serta uji linearitas dengan kriteria linearity $>$ taraf signifikansi $\alpha$.

c. Uji hipotesis, terdiri dari analisis regresi linear sederhana, uji korelasi koefisien sederhana, uji koefisien determinasi untuk mengetahui pengaruh $\mathrm{X}$ terhadap $\mathrm{Y}$, serta uji signifikansi korelasi (uji $\mathrm{T}$ ) untuk menguji signifikansi hipotesis penelitian. 


\section{HASIL DAN PEMBAHASAN}

Pembahasan hasil penelitian yang dilakukan melalui tahap pengumpulan, pengolahan dan analisis data adalah:

a. Uji validitas dan uji reliabilitas dilakukan kepada 87 orang. Kuesioner penelitian terdiri dari pernyataan yang terkait variabel kualitas pelayanan dan kepuasan masyarakat. Nilai r ritung $(0,1775)$ yang terdiri dari 43 pernyataan yang valid. Kuesioner pada penelitian ini dinyatkan reliable karena memiliki nilai untuk variabel kualitas pelayanan adalah 0,888 dan variabel kepuasan masyarakat adalah 0,879 .

b. Hasil rekapitulasi tanggapan responden diketahui nilai tertinggi dan terendah untuk variabel kualitas pelayanan (X) adalah pernyataan nomor 4 dengan skor 371 merupakan indikator bukti langsung (tangibles). Nilai terendah pada variabel kualitas pelayanan (X) adalah pernyataan nomor 8 dengan skor 306 merupakan indikator keandalan (reliability).

c. Perhitungan uji normalitas pada penelitian ini dilakukan dengan dua metode yaitu Kolmogorov Smirnov dan p-plot. Berikut hasil uji normalitas:

Tabel 1

Uji normalitas Kolmogorov Sminov

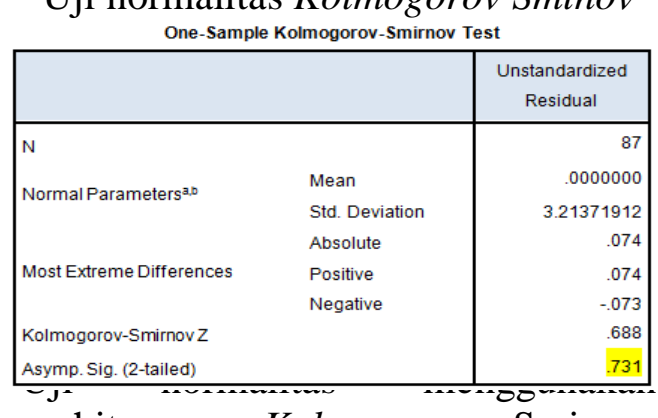

perhitungan Kolmogorov Smirnov menunjukan nilai sig sebesar 0,731 > nilai taraf signifikansi 0,1 , sehingga data penelitian berdisitribusi normal.

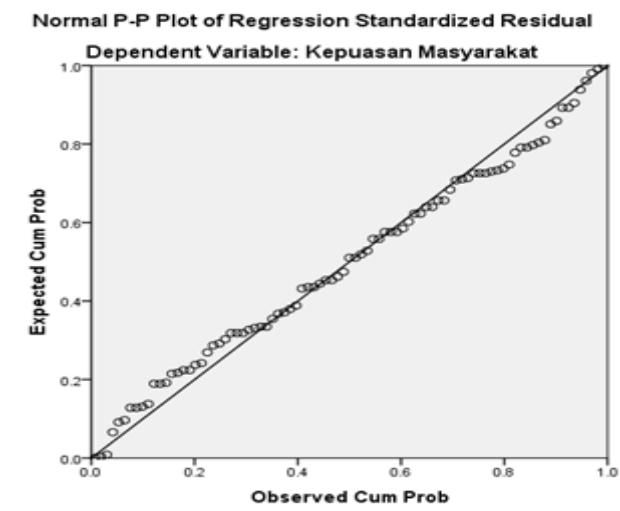

Gambar 1. P-plot (Sumber: data primer diolah, 2018)

Uji normalitas menggunakan grafik $P$ plot dapat dilihat bahwa data menyebar disekitar garis diagonal dan mengikuti arah garis diagonalnya, sehingga dapat disimpulkan model regeresi pada penelitian ini bersifat normal.

d. Hasil uji linearitas diperoleh nilai signifikansi linearitas sebesar 0,120. Nilai ini lebih besar dari taraf signifikansi penelitian sebesar 0,1 $(0,120>0,1)$ sehingga variabel kualitas pelayanan dan kepuasan masyarakat mempunyai hubungan yang linear atau searah.

Tabel 2

Hasil uji linearitas

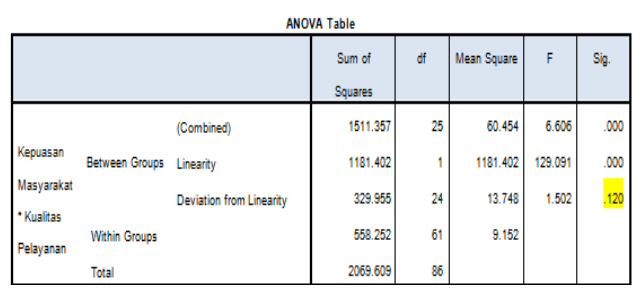

Sumber: data primer diolah, 2018

Sumber: data primer diolah, 2018

e. Hasil uji regresi linear sederhana diperoleh persamaan regresi $\mathrm{Y}=$ 17,756 + 0,536 X. hasil menunjukkan hasil yang positif dan linear, dimana setiap kenaikan satu nilai pada variabel kepuasan masyarakat (Y) akan diikuti kenaikan 0,464 pada variabel kualitas pelayanan (X). 
Tabel 3

Hasil uii regresi linear sederhana

\begin{tabular}{|c|c|c|c|c|c|}
\hline & Unstandadrdz & 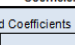 & 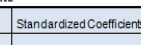 & i & |sig \\
\hline Constrit & 177.75 & 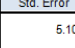 & & 3.48 & \\
\hline & .586 & & .7 & 10.83 & \\
\hline
\end{tabular}

Sumber: data primer diolah, 2018

f. Hasil perhitungan korelasi sederhana antara variabel kualitas pelayanan (X) dan kepuasan masyarakat (Y) adaah 0,756 sehingga dapat disimpulkan bahwa adanya hubungan atau korelasi yang kuat antara variabel kualitas pelayanan dan kepuasan masyarakat.

Tabel 4

Hasil uji korelasi sederhana

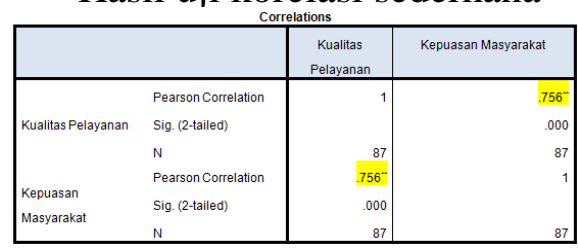

Sumber: data primer diolah, 2018

g. Uji koefisien determiniasi $\left(\mathrm{R}^{2}\right)$ diperoleh nilai sebesar 0,571 sehingga dapat disimpulkan bahwa variabel kualitas pelayanan (X) menyumbangkan pengaruh terhadap variabel kepuasan masyarakat (Y) sebesar $57,1 \%$ yang terdiri dari lima indikator yaitu, tangibles, reliability, responsiveness, assurance, dan emphaty namun, indikator yang paling berpengaruh adalah tangibles, sedangakan sisanya yaitu sebesar 42,9\% dipengaruhi oleh faktor lain yang tidak diteliti seperti, tingkat pendapatan masyarakat, pemasukan kas daerah dan harga tanah.

Tabel 5

Hasil uji determinasi $\left(\mathrm{R}^{2}\right)$

Model Summary

\begin{tabular}{|l|l|r|r|c|}
\hline Model & \multicolumn{1}{|c|}{$R$} & R Square & Adjusted R Square & \multicolumn{1}{c|}{ Std. Error of the Estimate } \\
\hline 1 & $.756^{3}$ & .571 & .566 & 3.23257 \\
\hline
\end{tabular}

Sumber: data primer diolah, 2018

h. Hasil perhitungan uji signifikansi korelasi (uji T) didapatkan nilai thitung $10,633>t_{\text {tabel }}$ 1,663. Sehingga H0 ditolak dan Ha diterima, dimana $\mathrm{Ha}$ adalah kualitas pelayanan perizinan di DPMPTSP Kabupaten Bogor mempunyai pengaruh yang signifikan terhadap kepuasan masyarakat.

Tabel 6

Hasil uji signifikansi (Uji T)

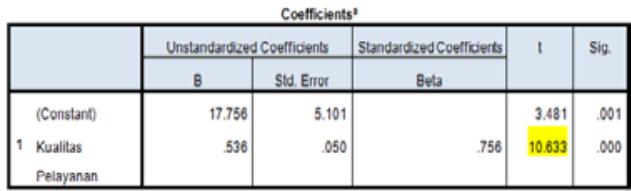

Sumber: data primer diolah, 2018

Berdasarkan pembahasan hasil analisis penelitian diatas, dapat dibuktikan hipotesis pada penelitian yaitu kualitas pelayanan perizinan di DPMPTSP Kabupaten Bogor mempunyai pengaruh yang signifikan terhadap kepuasan masyarakat. Hubungan yang diukur dari hasil penelitian ini menunjukkan hubungan yang linear, kuat, signifikan serta memiliki pengaruh yang positif antara kualitas pelayanan perizinan terhadap kepuasan masyarakat.

\section{KESIMPULAN DAN SARAN Kesimpulan}

Hasil penelitian terkait kualitas pelayanan perizinan terhadap kepuasan masyarakat yang dilakukan pada DPMPTSP Kabupaten Bogor adalah kualitas pelayanan perizinan berpengaruh terhadap kepuasan masyarakat pada DPMPTSP Kabupaten Bogor dilihat dari hasil analisis antara variabel kualitas pelayanan dan variabel kepuasan masyarakat menunjukkan bahwa kualitas pelayanan memiliki korelasi yang searah dengan kepuasan masyarakat. Variabel kualitas pelayanan mampu menciptakan hubungan yang kuat dan signifikan terhadap kepuasan masyarakat.

Adapun nilai hubungan kualitas pelayanan memberikan pengaruh sebesar $57,1 \%$ terhadap kepuasan masyarakat dalam penelitian ini, untuk Indikator yang mempunyai pengaruh besar terhadap kepuasan masyarakat adalah bukti langsung (tangibles) khususnya pada lokasi kantor DPMPTSP Kabupaten Bogor yang strategis, mudah dijangkau transportasi umum, fasilitas kantor dan 
perlengkapan pegawai sedangkan sisanya 42,9\% dipengaruhi oleh beberapa faktor lain di luar pembahasan penelitian seperti tingkat pendapatan masyarakat, pemasukan kas daerah dan harga tanah. Nilai (besaran) yang dihasilkan oleh variabel kualitas pelayanan memiliki kontribusi yang cukup besar untuk menimbulkan kepuasan masyarakat, akan tetapi nilai tersebut menunjukkan bahwa masih ada faktor-faktor lain selain variabel kualitas pelayanan yang mampu menciptakan kepuasan dari masyarakat, namun tidak dijelaskan pada penelitian ini mengingat adanya pembatasan masalah pada bahasan.

Berdasarkan hasil analisis jawaban responden pada variabel kualitas pelayanan, indikator yang menimbulkan hubungan paling kuat adalah indikator bukti fisik (tangibles) dengan nilai skor 371 yang berhubungan dengan lokasi kantor dan perlengkapan pegawai. Untuk hasil skor terendah variabel kualitas pelayanan adalah keandalah (reliability) dengan skor 306 berhubungan dengan kecepatan dan ketepatan pegawai dalam mengerjakan berkas perizinan yang sesuai dengan peraturan. Kenyamanan ruang tunggu pada indikator kepuasan fungsional untu variabel kepuasan masyarakat juga memiliki nilai yang rendah dengan skor 343.

\section{Saran}

Berdasarkan hasil penelitian dan kesimpulan yang telah dikemukakan, saran yang dapat diberikan adalah sebagai berikut:

a. DPMPTSP Kabupaten Bogor perlu melakukan peninjauan ulang kembali waktu penyelesaian berkas 7-14 hari kerja, karena masyarakat kurang puas terhadap penyelesaian berkas perizinan yang tidak sesuai dengan peraturan.

Untuk beberapa perizinan yang sifatnya tidak dibutuhkan rapat bidang dan peninjauan langsung mungkin bisa selesai sesuai peraturan seperti
SIUP, TDUP, izin reklame dan sebagainya. Namun, lain hal jika perizinan yang membutuhkan rapat bidang, peninjauan langsung lahan dan lain-lain seperti Izin Mendirikan Bangunan dan Gedung (IMBG), Izin Peruntukan Penggunaan Tanah (IPPT) dan lain-lain. jika perizinan belum selesai setelah melewati 14 hari kerja akan membuat masyarkat kecewa sehingga dapat menurunkan tingkat kepuasan masyarkat. DPMPTSP juga bisa memberikan pengertian kepada masyarkat di unit pengaduan yang tersedia sehingga masyarakat mengerti bahwa proses pembuatan perizinan memerlukan proses yang panjang.

b. DPMPTSP Kabupaten Bogor perlu mengganti sofa di ruang tunggu karena masyarakat kurang nyaman dengan ukruran sofa yang dinilai terlalu pendek untuk orang dewasa sehingga masyarakat tidak nyaman duduk di dalam ruang tunggu.

\section{UCAPAN TERIMA KASIH}

Penulis mengucapkan terima kasih kepada Pusat Penelitian Pengabdian Masyarakat (P3M) Politeknik Negeri Jakarta yang telah memberikan dana Bantuan Tugas Akhir Mahasiswa (BTAM) untuk pelaksanaan penelitian ini.

\section{DAFTAR PUSTAKA}

Buku:

Andy dan Oscar. 2017. New Public Service and Management. Jakarta: CV Pustaka Jaya

Kasmir. 2008. Etika Customer Service. Jakarta: PT Raja Grafindo

Kottler dan Keller. 2009. Manajemen Pemasaran, Edisi Ketiga Belas. Jakarta: Erlangga.

Mukarom dan Laksana. 2018. Manajemn Pelayanan Publik. Bandung: CV Pustaka Setia. 
Mukarom dan Laksana. 2016. Membangun Kinerja Pelayanan Publik. Bandung: CV Pustaka Setia.

Noor, Juliansyah. 2011. Metodologi Penelitian. Jakarta : Kencana

Penyusun, Tim. Peraturan Kepala Dinas Penanaman Modal dan Pelayanan Terpadu Satu Pintu. Tentang Standar Operasional Prosedur Pelayana Perizinan dan Nonperizinan Pada Dinas Penanaman Modal dan Pelayanan Terpadu Satu Pintu.

Penyusun, Tim. Peraturan Menteri Dalam Negeri Republik Indonesia Nomor 138 Tahun 2017 Tentang Penyelenggaraan Pelayanan Terpadu Satu Pintu Daerah.

Rahmayanty, Nina. 2010. Manajemen Pelayanan Prima. Yogyakarta: Graha Ilmu

Sanusi, Anwar. 2011. Metodologi Penelitian Bisnis. Jakarta : Salemba Empat

Sugiarto. 2017. Metodologi Penelitian Bisnis. Yogyakarta : CV. Andi Offset

Siregar, Syofian. 2014. Metode Penelitian Kuantitatif. Jakarta : Kencana

Sugiyono. 2017. Metode Penelitian Bisnis. Bandung: CV Alvabeta

Sugiyono. 2016. Metode Penelitian Kuantitatif, Kualitatif dan $\mathrm{RnD}$. Bandung:

CV Alvabeta.

Publik, No 2 (Januari 2017), Surakarta.

Rasyidin, Abdul Wahid. 2017. "Analisis Pelayanan Publik Dinas Penanaman Modal dan Pelayanan Terpadu Satu Pintu Kota Palopo”. Dalam Editor, (Novemer 2017), Palopo.
Sugiyono. 2010. Metode Penelitian Bisnis . Bandung: CV Alvabeta.

Tjiptono, Fandy. 2017. Service Management Mewujudkan Layanan Prima. Yogyakarta: CV Andi Ofset

Tjiptono, Fandy. 2008. Service Management Mewujudkan Layanan Prima. Yogyakarta: CV Andi Ofset.

Wijaya dan Danar. 2017. Manajemen Publik Ori dan Praktik. Malang:UB Proses

Wijaya, Tony. 2011. Manajemen Kualitas Jasa. Jakarta: Permata Puri Media

Wirman, Syafri. 2012. Studi Tentang Administrasi Publik. Jakarta: Erlangga.

Jurnal:

Enggarani, Nuria Siswi. 2016. "Kualitas Pelayanan Publik dalam Perizinan di Pelayanan Terpadu Satu Pintu (PTSP) Kantor Badan Penanaman Modal dan Pelayanan Perizinan Terpadu (BPMP2T) Kabupaten Boyolali". Dalam Editor, No 1 (Maret 2016), Boyolali.

Mustaghfiri, Mohammad Haidar dan Priyanto Susiloadi. 2017. "Kualitas Pelayanan Penerbitan Izin Mendirikan Bangunan di Dinas Penanaman Modal dan Pelayanan Terpadu Satu Pintu Kota Surakarta”. Dalam Jurnal Wacana

Website:

www.kpk.go.id/. Hasil Survey Intgritas Sektor Publik 2012. Diakses 13 April 2018 
